\title{
A Review on Perylene-3,4,9,10-Tetracarboxylic Acid Diimide Molecules
}

\author{
Özgül Birel* \\ Faculty of Sciences, Department of Chemistry, Muğla S1tkı Koçman University, \\ Kötekli-48121, Muğla/TURKEY, +90 2522111493 \\ ozgulbirel@mu.edu.tr \\ ${ }^{*}$ Corresponding author \\ Recieved: $1^{\text {th }}$ November 2016 \\ Kabul: $7^{\text {th }}$ January 2017 \\ DOI; $10.18466 /$ cbayarfbe.319879
}

\begin{abstract}
The aim of this article is to inform about perylene-3,4,9,10-tetracarboxylic acid dimide (PDI) derivatives. Also, it is to give short and simple information about optical properties and using fields. Perylene-3,4,9,10-tetracarboxylic acid dimide derivatives known as perylene diimides are material of highly conjugated molecule. PDIs exhibit strong absorptions within the range of 400-450 nm (B band) and 500-700 nm (Q band). Perylene diimide dyes show generally characteristic absorption peaks at $458,490,526 \mathrm{~nm}$. These absorption peaks are matched by the corresponding emission peaks at 540,576, $624 \mathrm{~nm}$, respectively. It has donor core and acceptor carbonyl groups. Perylene dimide has good electron mobility, high fluorescence quantum yields, strong absorption in the visible region, photostability, thermal stability, good semi-conductivity. These properties benefit them application of electronic material. Applications of PDIs are in the field of photo-electronic material, dye lasers, organic light-emitting diodes, and chemosensing materials.
\end{abstract}

Keywords-Dye, Organic based-solar cells (DSSC), perylene diimide, perylene monoimide, sensor

\section{Introduction}

Perylene-3,4,9,10-tetracarboxylic acid dimide derivatives known as perylene diimides are abbreviated as PDIs. PDI-chromophoric dye is one of the excellent materials of highly conjugated molecule [1]. It has donor core and acceptor carbonyl groups. Perylene3,4,9,10-tetracarboxylic dianhydride (PTCDA) is used to synthesis the perylene-3,4,9,10tetracarboxylic acid dimide. PDIs first reported in 1913 are known Pigment Red 179. Figure 1 shows molecular structures of PDI, PTCDA and Pigment Red 179.

Perylene diimides exist in a wide range of colors from red to violet, and even shades of black. Pigment Red 149 is a yellow shade red material, while Pigment Red 178 and Pigment Red 179 are of blue-shade red color. Figure 2 shows molecular structures of Pigment Red 149 and Pigment Red 178.

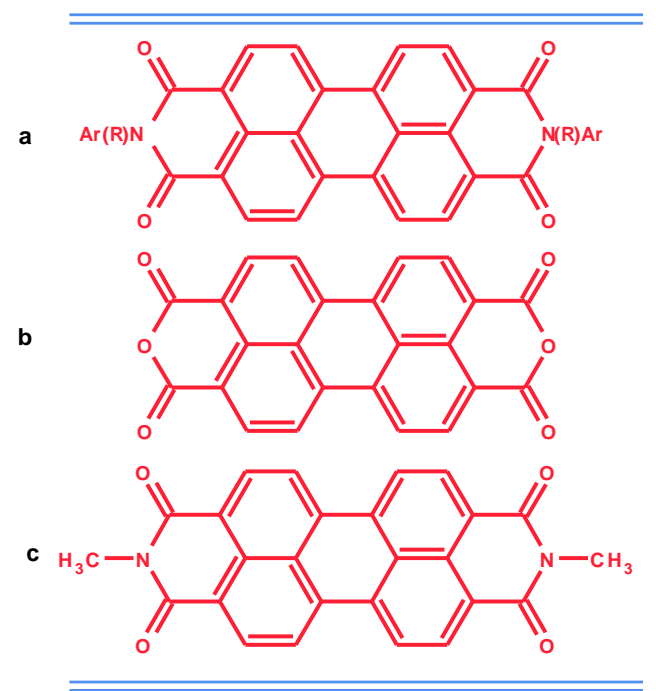

Figure 1. Molecular structures a) perylene dimide (PDI) b) perylene-3,4,9,10-tetracarboxylic dianhydride (PTCDA) c) pigment red $179\left(\mathrm{~N}, \mathrm{~N}^{\prime}\right.$-dimethyl PDI) 

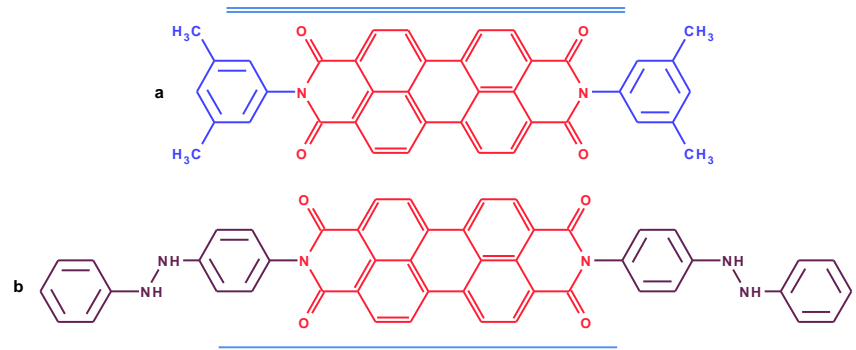

Figure 2. Molecular structures a) pigment red 149 b) pigment red 178

Different PDI derivatives are obtained from both imide and bay position. Some properties of PDI are tuned by modification of the substituent. While substituents on the imide nitrogen atoms have little effect on optical and electronic properties, it affects solubility. Bay substituents at the 1,6,7 or 12 positions affect electronic and optical properties and alter photo-physical properties of PDI [2,3]. The color of perylene diimides is tuned by variation of the substituent of the imide functions [4].

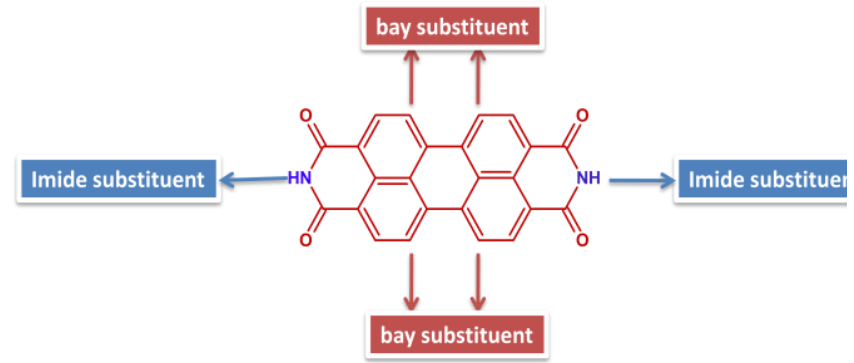

While PDI was initially used exclusively as industrial pigments as red vat dyes, nowadays applications of PDI are in the field of photo-electronic material, dye lasers, organic light-emitting diodes (OLED) [4,5], chemosensing materials [6], biosensing [7]. It has electron transporting character. Also, perylene diimides have been widely studied for biochemical and pharmacological purpose because of considiring as potential antitumor drugs acting as telomerase inhibitors [8]. Perylene dimide has good electron mobility [9], high fluorescence quantum yields [10], strong absorption in the visible region [11], photostability [12-14], thermal stability [15-18], large extinction coefficients, high electron affinity [4] and good semi-conductivity [19]. These properties benefit them application of electronic material [15]. PDIs exhibit strong absorptions within the range of 400$450 \mathrm{~nm}$ (B band) and 500-700 nm (Q band) [20] owing to their extended conjugated- $\Pi$ systems. The fluorescence quantum yields of PDIs are near 1.0 [14].

Symmetrical PDI derivatives are prepared by using perylene-3,4,9,10-

tetracarboxylicdianhydride(PTCDA) in solvents such as molten imidazole or quinoline by using anhydrous zinc acetate as a catalyst (Scheme 1). Appropriate PDI derivative in high yield forms the reaction between PTCDA and an alkyl/aniline amine. The soluble symmetrically $\mathrm{N}, \mathrm{N}^{\prime}$-substituted PDS are commonly obtained in the same way by using long chain alkyl groups. PDI molecules have insolubility problem in organic solvents [7].

Scheme 1. Preparation of symmetric PDI

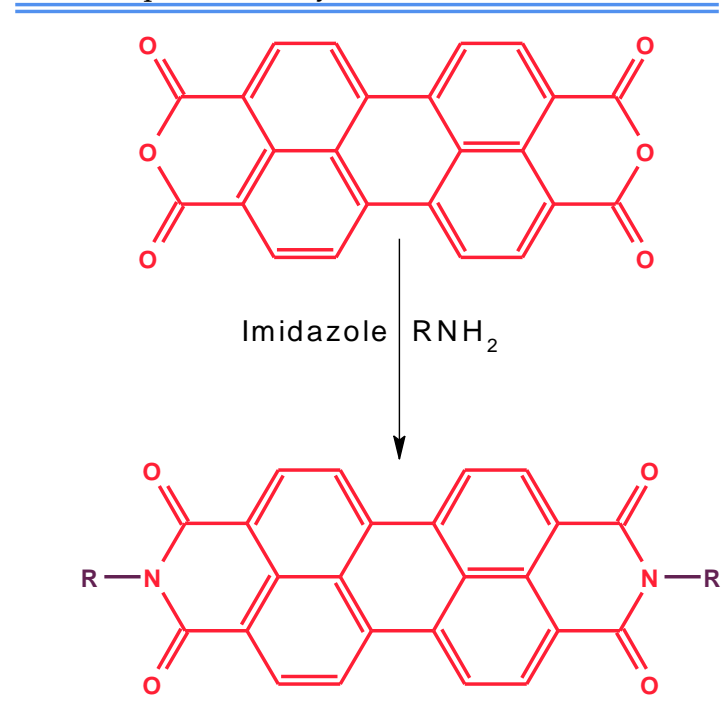

Unsymmetrical PDIs are synthesized by using PDI. Firstly, perylene monoimide monoanhydride is obtained to partial hydrolysis. Then, different amine is used for imidization to obtain desired asymmetrical PDI (Scheme 2).

Bay-substituted-PDI derivatives are prepared with introduction of aryl or aryloxy groups into the 1,6,7 or 12 (bay) positions of PDI. Solubility of PDI molecule increases. Also electronic and optical properties of PDI alter. PDI derivatives have good solubility in halogenated solvents such as dichloromethane, chloroform and chlorobenzene. Conjugated groups in the bay positions generally lead to bathochromically shifted spectra [2]. 
Scheme 2. Preparation of unsymmetric PDI

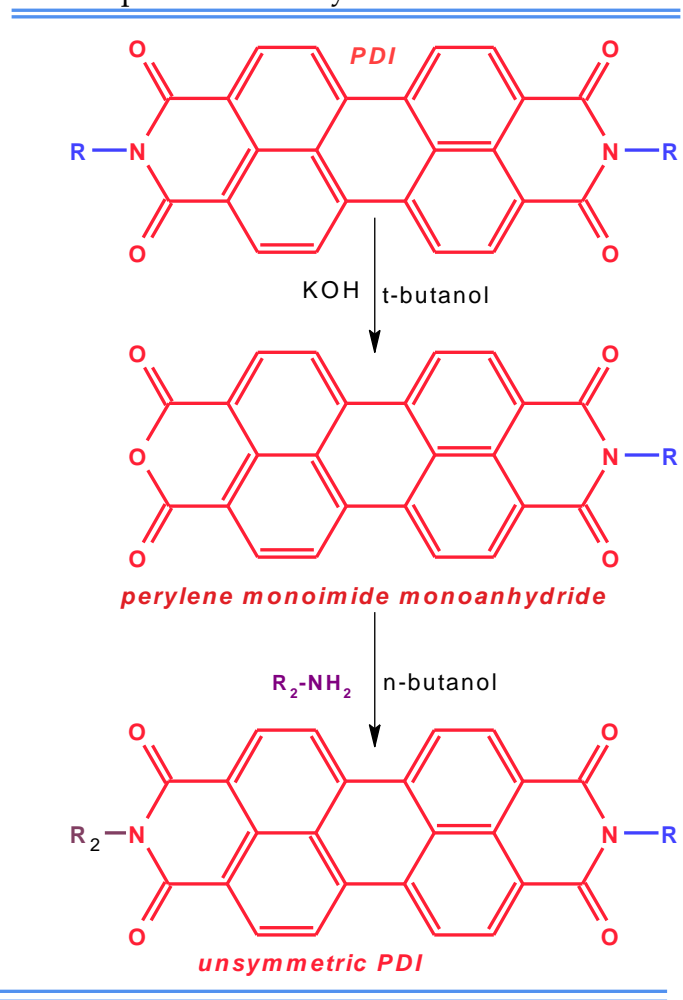

Perylene diimide dyes show generally characteristic absorption peaks for the perylene diimide at 458 , $490,526 \mathrm{~nm}$, which are denoted to their $(0,2),(0,1)$, and $(0,0)$ electronic transitions, respectively. These absorption peaks are matched by the corresponding emission peaks at 540,576, $624 \mathrm{~nm}$, respectively. The emission spectra of PDI fulfill the mirror image conditions to the absorption spectra in solutions. The perylene compounds show two reversible one electron reduction peaks. First reversible reduction wave was observed in the range of $-0.38 /-0.42 \mathrm{~V}$ and the second reduction potential was observed in the range of $0.57 /-0.62 \mathrm{~V}$. The reduction mechanism for the perylene dimide derivatives is known that electron transfer processes forms a radical anion occurs by the addition of an electron to the lowest LUMO and then the dianion with addition of a second electron to the same orbital. Redox behavior of the perylene dimide molecules is not affected significantly by $\mathrm{N}$ substituent [21].

In this paper, the structure, optical properties and application of some PDI derivatives from literature are reviewed.

Authors reported synthesis some of bay-perylene dimide derivatives (Figure 3). Zhang et al. have synthesized unsymmetrical PDI derivatives functionalizations at the 1,7 positions. It has absorption spectrum in the range of 556, 524 and $404 \mathrm{~nm}$ in Dichloromethane (DCM). It exhibits strongly fluorescent. The fluorescence peak is at $590 \mathrm{~nm}$. It shows the stronger electronic interactions between the electrondeficient core perylene and electron-rich alkoxy groups [22]. Handa et al. have synthesized 1,6 and 1,7 perylene diimides (PDIs) to obtain soluble molecule. It is possible to synthesis soluble perylene dimide via synthetic modification to $\mathrm{N}$-alkyl or aryl PDIs and/or by modification of the "bay" region $(1,6,7,12$ positions) [7]. PDI derivatives substituted at the bay positions are obtained by using $\mathrm{C}-\mathrm{O}, \mathrm{C}-\mathrm{C}$ and $\mathrm{C}-\mathrm{N}$ coupling. The steric hindrance and perylene core twisting induced by the bay substituents could prevent $\Pi$ - $\Pi^{*}$ stacking, and thus reduce luminescence quenching. Sivamurugan et al. have reported a series of perylenediimide derivatives with electron accepting substituents at the bay positions of the perylene core. Reaction yields are high (70-80\%). Author reported that perylene derivatives were found to be thermally stable up to ca. $440{ }^{\circ} \mathrm{C}$ with $5 \%$ weight loss temperature ranging from $436-460{ }^{\circ} \mathrm{C}$ [23].

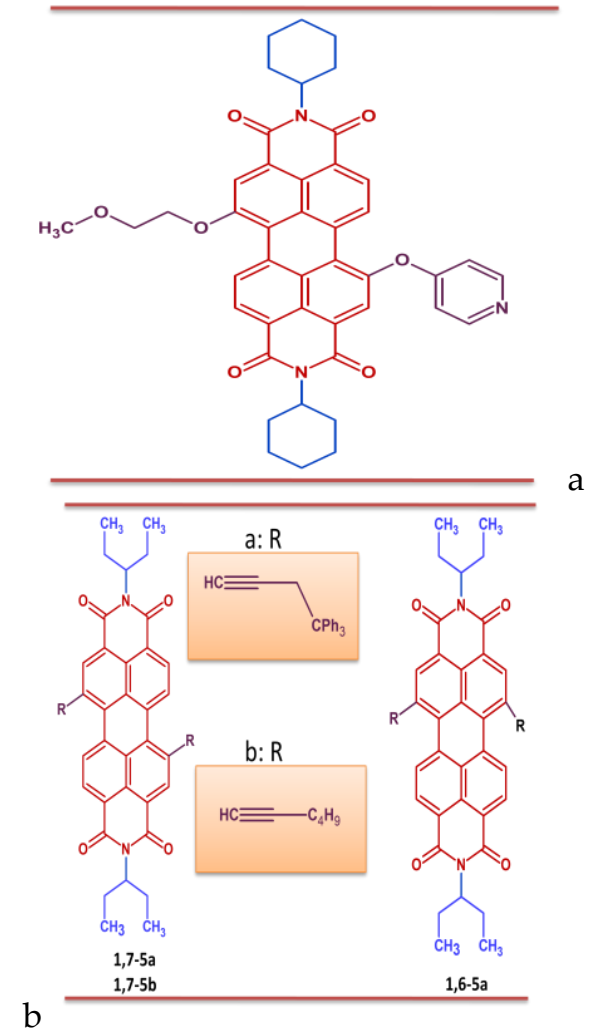




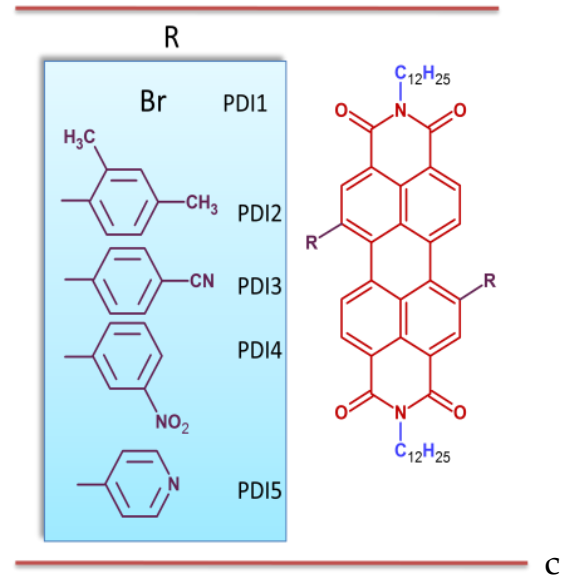

Figure 3. Molecular structures of bay-perylene dimide derivatives synthesis by a)Zhang et.al. b)Handa et al. c) Sivamurgan et al.

The highly soluble bay-perylene dimide containing $\alpha$ and $\beta$ linked thiophene group have synthesized by Balaji et al. (Figure 3). Oligothiophenes are donor structure with charge transport properties. Both molecules exhibit two absorption maxima with a weak low energy absorption band around $650 \mathrm{~nm}$. Author reported that the absorption spectrum of $\alpha$ linked bay perylene dimide is blue-shifted compared to the $\beta$ linked bay-perylene dimide. Author explained that this may be due to the branched nature of the thiophene degment, which prevents the effective conjugation of the pentathiophene. PDI molecules exhibit fluorescence properties but $\alpha$-linked and $\beta$ linked bay perylene thiophene dimide derivatives have not fluorescence properties. This is possible to photoinduced intramolecular electron transfer between the oligothiophene moiety and the perylene core [24]. The solubility of PDI molecules is limited. Its solubility can be improved by introducing solubilizing N-substituent with the long-tail or swallow-tail [26]. For a biological application, the water solubility of PDI is essential. Chromophores reported are groups such as sulphonic acid part, quaternized amine groups, polyethylene glycol [27].

Figure 5 shows a typical absorption and emission spectrum of PDI molecules. Perylene diimide dyes show generally characteristic absorption peaks for the perylene diimide at $458,490,526 \mathrm{~nm}$. These absorption peaks are matched by the corresponding emission peaks at 540, 576, $624 \mathrm{~nm}$, respectively. The emission spectra of PDI fulfill the mirror image con- ditions to the absorption spectra in solutions.

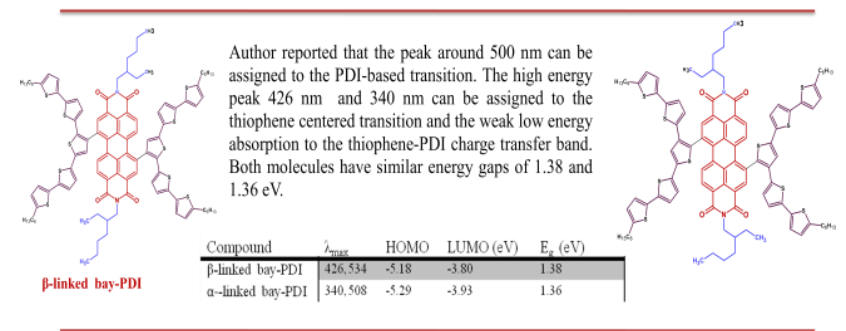

Figure 4. Molecular structures of bay-perylene dimide derivatives synthesized by Balaji et al.

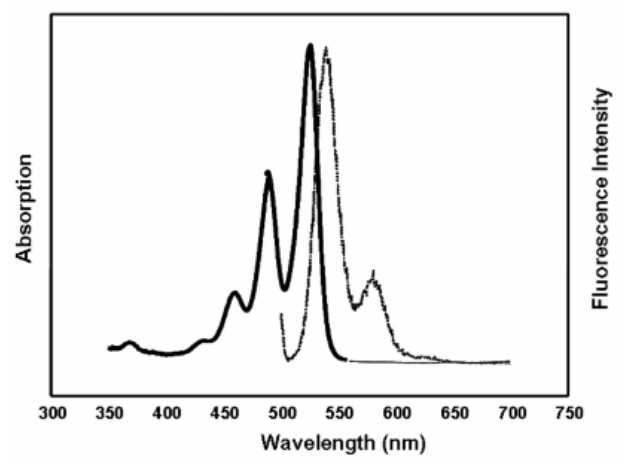

Figure 5. UV-Vis absorption (solid line) and emission (dashed line) spectra of a typical PDI in chloroform

PDI solution concentration in solvent is prepared as $10^{-5} \mathrm{M}$ to prevent reabsorption and concentration quenching. Absorbance values must be lower than 0,2 . Generally, perylene dimide molecules have three absorption bands $(\lambda=458 \mathrm{~nm}, 490 \mathrm{~nm}, 526 \mathrm{~nm})$ and high absorptivite coefficient $\left(\varepsilon=10^{5}\right)$. They have strong absorption capacity at the visible region. As the conjugation increases, bathocromic shift occurs. Fluorescence quantum yield is about 1 [25]. The electronic nature of aryl substituents in the 2,5,8,11positions also has a significant impact on the optical properties of PDIs [2].

Wang et al. have synthesized fluorinated on the bay position of perylene diimide. Fluorine has electron affinity. Author reported that highly fluorinated materials display a variety of interesting properties such as thermal and chemical stability, low surface energy and high resistance to oxidation. Author reported that BFPDIs showed an increase in the first reduction potential, indicating that the electron accepting power increased in strength. LUMO levels of BPPDI, 
BFPDI-1 and PFPDI-2 were calculated as $-3.85 \mathrm{eV}$, $4.00 \mathrm{eV}$ and $-4.02 \mathrm{eV}$, respectively. The decreased LUMO levels are ascribed to the electron-deficient fluorinated substituents on the bay of perylene diimides. Three PDI molecules are highly soluble in water. So absorption spectra were taken in both water and toluene. Absorption bands of BPPDI measured in toluene are at $551 \mathrm{~nm}$ and $518 \mathrm{~nm}$. Absorption bands measured in toluene are at $542 \mathrm{~nm}$ for BFPDI-1 and $539 \mathrm{~nm}$ for BFPDI-2. It shows blueschifted. Absorption spectra values taken in water are $557 \mathrm{~nm}$ for BPPDI, $550 \mathrm{~nm}$ for BFPDI-1 and 548 $\mathrm{nm}$ for BFPDI-2. It shows red-schifted [28].

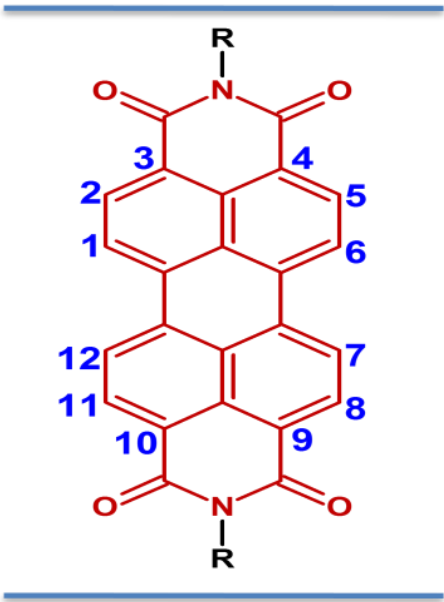

Figure 6. Chemical structure of PDI showing the numbering of the positions in the ring system

It is reported synthesis of unsymmetric triazinelinked porphyrine perylene dimide molecule. Also, porphyrin molecules are sensitizer for chemical and biological sensors. Perylenes are common electron acceptor in porphyrin donor-acceptor systems due to their low LUMO. The intense absorption bands of perylene derivatives are between porphyrin's Soret band and $Q$ bands, thus perylene can enhance the absorption efficiency of the sunlight and is thought to be beter acceptor candidate.

The LUMO and HOMO energy levels for HTPP-PDI are $-4.05 \mathrm{eV}$ and $-5.68 \mathrm{eV}$, respectively. Both HOMO and LUMO levels of porphyrin derivatives are higher than those of perylene derivatives, indicating a possible electron transfer from porphyrins to perylene. It is reported that HTPP-PDI, the HOMO locates on the porphyrin moiety while the LUMO locates on the perylene moiety [29].

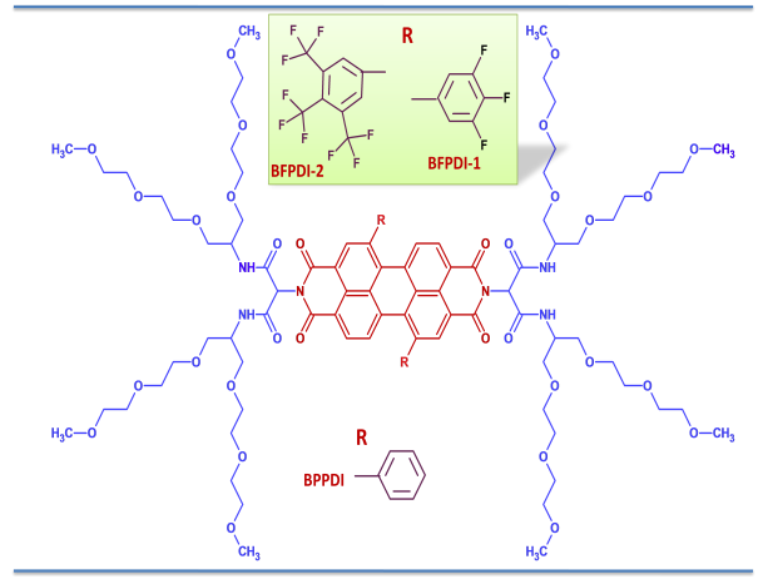

Figure 7. Molecular structures of fluorinated-perylene dimide derivatives synthesized by Wang et al.

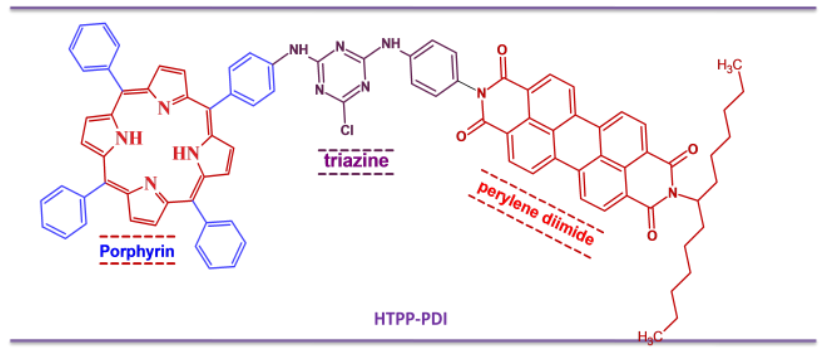

Figure 8. Molecular structure of porphyrin-perylene dimide derivatives synthesized by Zhou et al.

Perylene dimides are used as a sensor. It is reported that rhodamine-perylene dimide fluorescent probe has been synthesized for cell imaging. The perylene dimide chromophore plays as an electron acceptor, the rhodamine units serve as electron donors and the ethylene-diamine plays as spacer [30]. Zhao et al. have used cationic-perylene-G-quadruplex complex based fluorescent biosensor for detection of $\mathrm{Pb}^{2+}$ [31]. $\mathrm{Hg}^{2+}$ sensor was developed by Cheng et al.[32]. It is reported that perylene dimide derivatives are used for $\mathrm{Cu}^{2+}$ probe [33].

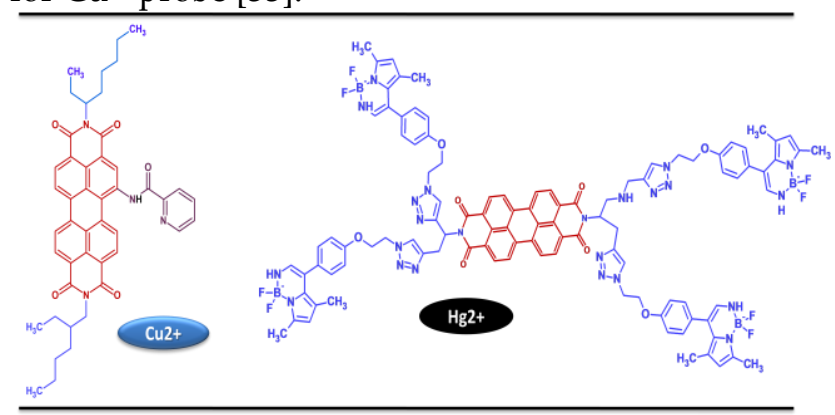

Figure 9. Molecular structures of perylene dimide derivatives for sensors. 
Solar cells, also called photovoltaic cells, are an electronic device used to generate electricity directly from sunlight. Dye-sensitized solar cells (DSSCs) have attracted alternative to the conventional photovoltaic cell due to low-cost electricity production from sun light, high power conversion efficiency for solar energy. Perylene dimide derivatives are used for DSSC [34]. Figure 10 shows some perylene derivatives for DSSC and power conversion efficiency (PCE), electrochemical, optical properties [35-37].

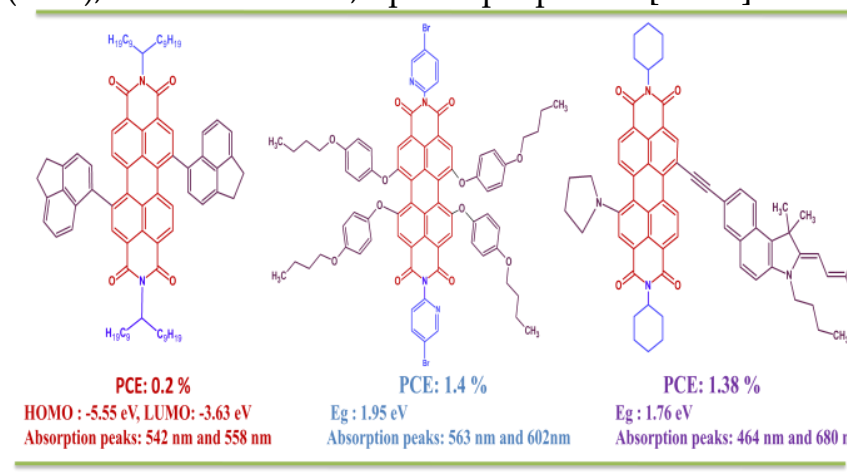

Figure 10. Molecular structures of perylene dimide derivatives for DSSC

Unsymmetrically N-Butyl-N'-(6-hydroxyhexyl) perylene-3,4,9,10-tetracarboxylic acid dimide $(\mathrm{N}$ BuHHPDI) has been synthesized in high yield by Tahir et all. Perylene-3,4,9,10-tetracarboxylic dianhydride (PTCDA) is partial hydrolized with $\mathrm{KOH}$. Then, it is obtained potassium salt. Perylene monoimide is obtained by using n-buthyl amine. Other side of perylene molecule is anhydride. Then, different amine is used for imidization to obtain desired asymmetrical PDI [38].

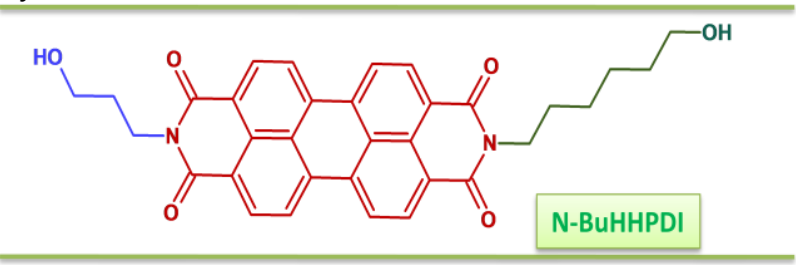

Figure 11. Molecular structure of PDI derivatives synthesized by Kozma et al.

\section{CONCLUSION}

Organic dye perylene-3,4,9,10-tetracarboxylic acid dimide derivatives are also known as perylene diimides. Perylene diimide dyes show generally characteristic absorption peaks for the perylene diimide at $458,490,526 \mathrm{~nm}$, which are denoted to their $(0,2),(0,1)$, and $(0,0)$ electronic transitions, re- spectively. These absorption peaks are matched by the corresponding emission peaks at 540, 576, 624 $\mathrm{nm}$, respectively. The perylene compounds show two reversible one electron reduction peaks. Nowadays applications of PDI are in the field of photoelectronic material, dye lasers, organic light-emitting diodes, chemosensing materials, biosensing.

\section{REFERENCES}

[1] Aleshinloye, A.O.; Bodapati, J. B.; Icil, H. Synthesis, Characterization, Optical and Electrochemical Properties of a New Chiral Multichromophoric System Based on Perylene and Naphthalene Diimides. Journal of Photochemistry and PhotobiologybA: Chemistry. 2015; 300, 27-37.

[2] Huang, C.; Barlow, S.; Marder, S.R. Perylene3,4,9,10-tetracarboxylic Acid Diimides: Synthesis, Physical Properties, and Use in Organic Electronics. The Journal of Organic Chemistry. 2011; 76, 23862407.

[3] Zhao,H.; Zhang, Y.; Xu, H.; He, Z.; Zhang, Z.; Zhang, H. Synthesis and Properties of Perylene Diimide Dyes Bearing Unsymmetrical and Symmetrical Phenoxy Substituents at Bay Positions. Tetrahedron. 2015; 71, 7752-7757.

[4] Saeed, A.; Shabir, G.; Mahar, J.; Irfan, M. Spectroscopic and Electrochemical Behavior of Newly Synthesized High Fluorescent Symmetric 4'-nitrophenyl3,4,9,10-perylenebisdiimide-azo Hybrid Dyes. Spectrochimica Acta Part A: Molecular and Biomolecular Spectroscopy. 2015; 151, 72-79.

[5] Rachford, A.A.; Goeb, S.; Castellano, F.N. Accesing the Excited State in Perylenediimides. American Chemical Society. 2008; 130, 2766-2767.

[6] Georgiev, N.I.; Sakr, A.R.; Bojinov.V.B. Design and Synthesis of Novel Fluorescence Sensing Perylene Diimides Based on Photoinduced Electron Transfer. Dyes and Pigments. 2011; 91, 332-339.

[7] Handa, N.V.; Mendoza, K.D.; Shietcliff, L.D. Syntheses and Properties of 1,6 and 1,7 Perylenediimides and Tetracarboxylic Dianhydrides. Org.Lett. 2011; 
13(17), 332-339.

[8] Boobalan, G.; Imran, P.M.; Nagarajan, S. Synthesis of Highly Fluorescent and Water Soluble Perylene Bisimide. Chinese Chemical Letters. 2012; 23, 149153.

[9] Liu,Y.; Wang, Y.; Ai, L.; Liu, Z.; Ouyang, X.; Ge, Z. Perylenebisimide Regioisomers: Effect of Substituent Position on Their Spectroscopic, Electrochemical, and Photovoltaic Properties. Dyes and Pigments. 2015; 121, 363-371.

[10] Zhang, R.; Wang, Z.; Wu, Y.; Fu, H.; Yao, J. A Novel Redox-Fluorescence Switch Based on a Triad Containing Ferrocene and Perylene Dimide Units. Org.Lett. 2008; 121(10), 3065-3068.

[11] Handa, N.V.; Shirtcliff, L.D.; Berlin, K.D. Synthesis, Photophysical, and Electrochemical Properties of Hamilton Receptor Functionalized Perylene Diimides. Tetrahedron Letters. 2015; 56, 445-451.

[12] Lv, Z.; Liu, J.; Bai, W.; Yang, S.; Chen, A. A Simple and Sensitive Label-Free Fluorescent Approach for Protein Detection Based on a Perylene Probe and Aptamer. Biosensors and Bioelectronics. 2015; 64, 530-534.

[13] Dias, M.; Hudhomme, P.; Levillain, E.; Perrin, L.; Sahin, Y.; Sauvage, F.; Wartelle, C. Electrochemistry Coupled to Fluorescence Spectroscopy: a New Versatile Approach. Electrochemistry Communications. 2004; 6, 325-330.

[14] Lee, S.K.; Zu, Y.; Herrmann, A.; Geerts, Y.; Müllen, K.; and Bard, A.J. Electrochemistry, Spectroscopy and Electrogenerated Chemiluminescence of Perylene, Terrylene, and Quaterrylene diimides in Aprotic Solution. J.Am.Chem.Soc. 1999; 121, 35133520.

[15] Yu, Y.; Li, Y.; Qin, Z.; Jiang, R.; Liu, H.; Li, Y. Designed Synthesis and Supramolecular Architectures of furan-substituted Perylene Dimide. Journal of Colloid and Interface Science. 2013; 399, 13-18.

[16] Tahir, M.; Sayyad, M.H.; Wahab, F.; Aziz, F.;
Shahid, M.; Munawar, M.A. Perylene Diimide: Synthesis, Fabrication and Temperature Dependent Electrical Characterization of Heterojunction with psilicon. Physica B: Condensed Matter. 2013; 426, 6-12.

[17] Mikroyannidis, J.A.; Stylianakis, M.M.; Sharma, G.D.; Balraju, P.; Roy, M.S. A novel Alternating Phenylenevinylene Copolymer with Perylene Bisimide Units: Synthesis, Photophysical, Electrochemical, and Photovoltaic Properties. The Journal of Physical Chemistry C. 2009; 113, 7904-7912.

[18] Kaya, İ.; Koyuncu, S.; Çulhaoğlu, S. Synthesis and Characterization of Novel Polyazomethines Containing Perylene Units. Polymer. 2008; 49, 703-714.

[19] Chen, Y.; Kong, Y.; Wang, Y.; Ma, P.; Bao, M.; Li, $X$. Supramolecular Self-assembly Study of a Flexible Perylenetetracarboxylic Dimide Dimer in Langmuir and Langmuir-blodgett Films. Journal of Colloid and Interface Science. 2009; 330, 421-427.

[20] Dinçalp, H.; Çimen, O.; Ameri, T.; Brabec, C.J.; İçli, S. Synthesis, Characterization and Optoelectronic Properties of a New Perylene diimidebenzimidazole Type Solar Light Harvesting Dye. Spectrochimica Acta Part A: Molecular and Biomolecular Spectroscopy. 2014; 128, 197-206.

[21] Birel, O.H.; Zafer, C.; Dincalp, H.; Aydın, B.; Can, M. Highly Soluble Polyoxyethylene-perylene Diimide: Optical, Electrochemical and Photovoltaic Studies. J.Chem.Soc.Pak. 2011; 33(4), 562-569.

[22] Zhang, X.; Pang, S.; Zhang, Z.; Ding, X.; Zhang, S.; He, S.; Zhan, C. Facile Synthesis of 1-bromo-7alkoxyl Perylene Diimide Dyes: Toward Unsymmetrical Functionalizations at the 1,7-positions. Tetrahedron Letters. 2012; 53, 1094-1097.

[23] Sivamurugan, V.; Kazlauskas, K.; Jursenas, S.; Gruodis, A.; Simokaitiene, J.; Grazulevicius, J.V.; Valiyaveettil, S. Synthesis and Photophysical Properties of Glass-forming Bay-substituted Perylenediimide Derivatives. J.Phys.Chem. 2010; 114, 17821789.

[24] Balaji, G.; Kale, T.S.; Keerthi, A.; Pelle, A.M.D.; 
Thayumanavan, S.; and Valiyaveettil, S. Low Band Gap Thiophene-perylene Diimide Systems with Tunable Charge Transport Properties. Organic Letters. 2011; 13(1), 18-21.

[25] Haklı, Ö., Synthesis of Perylene Dimide Derivatives and Studies on Photophysical Properties of Perylene Diimides and Some Vitamine-K3 Derivatives: Stability Tests Under Concentrated Sun Light (Ph.D. thesis), Ege University.Chemistry Department, Izmir. 2006.

[26] Yang, L.; Shi, M.; Wang, M.; Chen, H. Synthesis, Electrochemical, and Spectroscopic Properties of Soluble Perylene Monoimide Diesters. Tetrahedron. 2008; 64, 5404-5409.

[27] Bryaskova, R.; Georgiev, N.I.; Dimov, S.M.; Tzoneva, R.; Detrembleur, C.; Asiri, A.M.; Alamry, K.A.; Bojinov, V.B. Novel Nanosized Water Soluble Fluorescent Micelles with Embedded Perylene Diimide Fluorophores for Potential Biomedical Applications: Cell Permeability, Localization and Cytotoxicity. Materials Science and Engineering: C. 2015; 51, 7-15.

[28] Wang, J.; Zhong, S.; Duan, W.; Gao, B. Fluorinated Perylene Diimides: Synthesis, ElectrochemicalPhotophysical Properties, and Cellular Imaging. Tetrahedron Letters. 2015; 56, 824-827.

[29] Zhou, X.; Liu, D.; Wang, T.; Hu, X.; Guo, J.; Weerasinghe, K.C.; Wang, L.; Li, W. Synthesis and Photophysical Studies of Triazine-linked PorphyrinPerylene Bisimide Dyad with Long-lived Perylene Triplet State. Journal of Photochemistry and Photobiology A: Chemistry. 2014; 274 ,57-63.

[30] Cheng, H.R.; Qian, Y. Two Novel RhodaminePerylenediimide Fluorescent Probes: Synthesis, Photophysical Properties, and Cell Imaging. Chinese Chemical Letters. 2016; http://dx.doi.org/10.1016/j.cclet.2016.01.039.
[31] Zhao, X.H.; Gong, L.; Wu, Y.; Zhang, X.B.; Xie, J. Cationic-perylene-G-quadruplex Complex Based Fluorescent Biosensor for Label-free Detection of $\mathrm{Pb}^{2+}$. Talanta. 2016; 149, 98-102.

[32] Cheng, H.; Qian, Y. Intramolecular Fluorescence Resonance Energy Transfer in a Novel PDI-BODIPY Dendritic Structure: Synthesis, $\mathrm{Hg}^{2+}$ Sensor and Living Cell Imaging. Sensors and Actuators B. 2015; 219,57-64.

[33] Wang, Y.; Zhang, L.; Zhang, G.; Wu, Y.; Wu, S.; $\mathrm{Yu}, \mathrm{J}$.; Wang, L. A New Colorimetric and Fluorescent Bifunctional Probe for $\mathrm{Cu}^{2+}$ and $\mathrm{F}^{-}$Ions Based on Perylene Bisimide Derivatives. Tetrahedron Letters. 2014; 55, 3218-3222.

[34] Birel Ö., An Overwiew on the Some Phenothizanie Derivative Molecules used in Organic Dye-sensitized Solar Cells. Electronic Journal of Vocational Colleges. 2015.

[35] Kozma, E.; Kotowski, D.; Catellani, M.; Luzzati, S.; Famulari, A.; Bertini, F.S ynthesis and Characterization of New Electron Acceptor Perylene Dimide Molecules for Photovoltaic Applications. Dyes and Pigments, 2013; 99, 329-338.

[36] Jeonga, S.; Hana, Y.S.; Kwonb, Y.; Choic, M.S.; Chod, G.; Kime, K.S.; Kimd, Y. Effects of n-type Perylene Derivative as an Additive on the Power Conversion Effiencies of Polymer Solar Cells. Synthetic Metals, 2010; 160, 2109-2115

[37] Jin, Y.; Hua, J.; Wu, W.; Ma, X.; Meng, F. Synthesis, Characterization and Photovoltaic Properties of Two Novel Near-infrared Absorbing Perylene Dyes Containing benzo[e]indole for Dye-sensitized Solar Cells. Synthetic Metals, 2008; 158, 64-71.

[38] Tahir,M.; Sayyad, M.H.; Wahab, F.; Aziz, F.; Shahid, M.; Munawar, M.A.; Perylene Dimide: Synthesis, Fabrication and Temperature Dependent Electrical Characterization of Heterojunction with psilicon. Physica B. 2013; 426, 6-12. 